\title{
Seasonal Changes in Biomass of Calanus finmarchicus in the Plymouth Area in 1930.
}

\author{
By \\ B. G. Bogorov, \\ Plankton Laboratory, State Oceanographical Institute, Moscow.
}

With 8 Figures in the Text.

THIs paper deals with seasonal changes in the biomass of the copepod, Calanus finmarchicus. The work was carried out at the end of 1930 in the Laboratory of the Marine Biological Association at Plymouth with all the material of 1930 at my disposal.*

I take this opportunity of expressing my sincere thanks to the Director of the Plymouth Laboratory, Dr. E. J. Allen, for his ready assistance and for permission to work in the laboratory. I am much indebted, too, to E. Ford, V. A. Jaschnov, L. A. Zenkewitch for their valuable advice; particularly my heartiest thanks are due to F. S. Russell for supplying me with material and for the great assistance he has invariably given me throughout the present work.

"By biomass (Demoll) we term the quantity of substance in living organisms per unit of surface or volume. The biomass may be considered at some particular moment, the average yearly, seasonal, monthly, etc." (L. A. Zenkewitch, 1931.)

Weighing is the main method of obtaining the biomass. The conception "biomass" may be applicable also to the quantity of substance, characteristic for a given species at its different stages of development; it may even be applied to a single specimen. It is to be understood, then, that by biomass of a species or organism I mean here the quantity of substance in a living organism at a given moment. This quantity of substance is a characteristic of a given species just as are its size and morphological characters. The variations of biomass with seasons, locality, or in connection with age or different conditions of the medium, and the quantity of substance available for the species and the fluctuations of this quantity from stage to stage, form a definite complex, the study of which is a great problem.

* Interesting papers by Marshall and Nicholls have appeared recently in the Journal of the Marine Biological Association (Vol. XIX, No. 1, August, 1933) in which some of the questions discussed in the present paper are considered and confirmed.

NEW SERIES.-VOL. XIX. NO. 2. MAY, 1934. 
The determination of the biomass of plankton organisms is of no small importance as a means for the quantitative investigation of the biomass of the plankton. At present quantitative investigations on the biomass of the plankton must be conducted so as to show the weight value of separate components in the total biomass of the plankton, or in the food ration of the plankton-feeding organism (consumption of plankton). The solution of this problem depends on a knowledge of the fluctuation of the biomass, since the plankton community is exceedingly changeable both in time and space. The same quantity of biomass may be formed of different components. One efficient method is to use the average weight, i.e. the biomass of a given species of plankton organism, as a coefficient for finding the weight, when the number of specimens is known. Thus we obtain the biomass of each component and of the whole plankton sample, and the relation of the given component to the total biomass. This relates equally to the food of plankton-consuming organisms. Thus plankton in any sea area or fresh-water basin and plankton as food are comparable-both sides of the investigation of the plankton biomass being solved by making use of the same coefficients (average value of the plankton organism's biomass).

Attempts to estimate the weight of plankton organisms were made long ago. Apstein (1896) gives a number of determinations for specimens of the fresh-water plankton; Hensen (1887) records data on marine plankton; Vernadsky and Vinogradov (1927) have emphasized the necessity of characterizing each species by average weight. But these attempts were not systematic ; moreover they have not been applied to investigations of the plankton biomass in order to elicit the role of the separate components. Therefore the investigation of the biomass of plankton lags behind similar investigations on the benthos and the feeding of the benthos-consuming organisms. It is impossible to apply the methods used in the study of benthos to plankton investigations for purely technical reasons. The examination of each plankton sample, or food supply, of a plankton-consuming organism, would take too much time; the selected quantity of each species also does not guarantee the possibility of weighing it on account of its minute weight.

Therefore, without finally deciding on the method of estimating the average biomass of the species, whether it be selection of great quantities of a given species in the case of the larger forms, or the weighing of whole cultures of the smaller forms, especially in phytoplankton, or the estimation of the biomass of the organism on the basis of body-volume-I myself consider the method of estimating plankton biomass described above as fundamental if the question is to be attacked from the view-point of dynamics.

The apparent technical difficulties of obtaining the biomass of the 
plankton organism are in fact not so difficult to overcome. The advantage of such determinations - the biomass having been once found for the organisms of a given area-lies in the possibility of applying the obtained values to further investigations, connected with the estimation of the quantity of substance (biomass). Also old quantitative data on the plankton may be used. This calculation may be made at present in round figures, using the range of the quantity of the biomass of the plankton organism so that the different fluctuations in the biomass of any organism do not affect the total biomass of the whole plankton and its separate groups. It is, however, of considerable interest for further detailed estimations of the plankton biomass in that it raises various questions of the actual problem of " organism and medium."

\section{Material.}

The material was obtained by regular half-hour oblique hauls with the 2-metre stramin ring-trawl two miles east of the Eddystone Lighthouse during 1930. Since the hauls were made with a large-meshed net only the largest copepodite Stages IV, V, VI males and females of Calanus finmarchicus were caught; Stage IV was barely represented.

The material upon which I worked was collected on the following dates: February: 12th, 19th, and 26th. March: 5th, 12th, and 27th. April : 11th, 16th, 24th. May: 7th, 15th, and 22nd. June : 10th, 19th, and 26th. July: 4th and 9th. August: 7th. September: 3rd and 16th. October: 1st, 14th, and 16th. November: 13th and 26th; and December : 3rd, 10th, 17th, and 22nd.

\section{Methods.}

I made the following determinations : raw weight; dry weight ; and length of the body.

The weighing of live specimens presents a number of difficulties, and fixed specimens were used instead. Our material was fixed in formalin. The use of other fixatives may strongly affect the material (Vinogradov, 1927).

1. Raw weight was determined according to the quantity of material available in the following manner :

(a) When material was scarce (up to 300 specimens per sample) all copepodid stages in the sample were selected separately; the selected quantity was then divided into 2-3 portions according to the number of specimens of a given stage, and each portion was weighed separately.

(b) When a given stage was numerous five portions were taken, each containing not less than 100 specimens of each stage.

The preparation of specimens for raw weighing is of paramount importance. To obtain the raw weight all the moisture must be taken off the 
body; this is no easy task. The usual method of drying in filter-paper (Bogorov, 1933) depends greatly on the individual capacities of the worker and on the conditions under which the weighing is performed; thus the results obtained are not always suitable for comparison, being no more than an index of the range of value of biomass. These deficiencies in the filter-paper method stimulated the working-out of more efficient methods, and I worked out such a method with the kind help of E. M. Kreps.

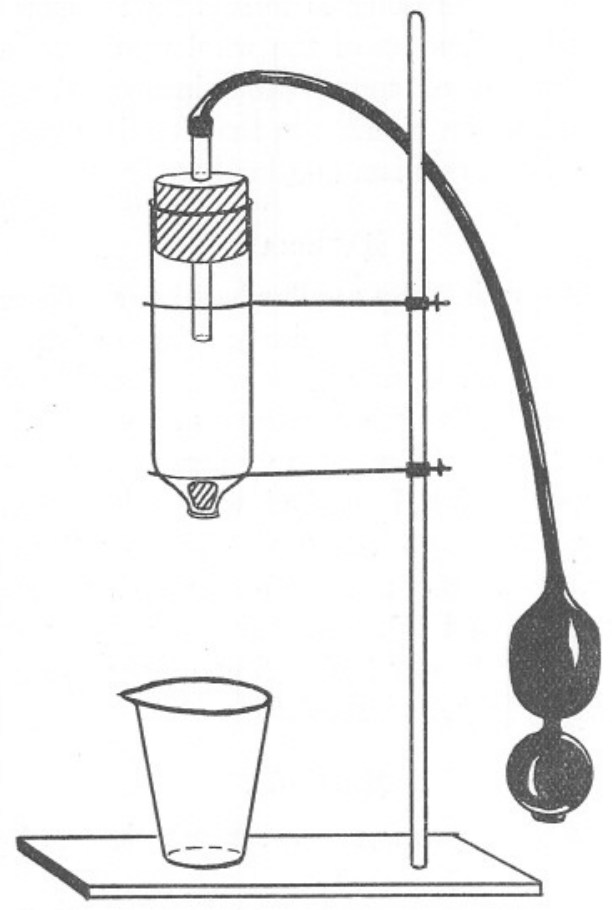

FIG. 1.-Device for "liquid" drying, to drive away water from the body-surface.

This method was based on the driving away of the moisture of the body surface by means of a dripping liquid. A device was constructed as follows: A small test-tube, not over 10 c.c., with a conical bottom and a hole in the apex of the cone, is fixed in a support. A glass ball, closing the lower aperture is placed at the bottom of the test-tube. The sides of the ball are somewhat flattened, forming facets, so as to let the liquid run freely out of the tube; but these facets must be of such a size that none of the specimens are washed out of the tube with the dripping liquid. This test-tube is stopped at the top by a cork, with a glass tube connected by rubber tubing with an air-pumping balloon (Fig. 1).

A weighed portion of the organisms was placed at the bottom of the 
tube; after all the water, brought with the portion, had been driven down the aperture of the tube, 1 c.c. of $90 \%$ alcohol was poured into the test-tube which, running down in a few seconds, brought away all the moisture of the body surface. Then 1 c.c. of ether was poured into the test-tube; the ether, running down rapidly, drove away the remaining alcohol. Then the test-tube was stopped, and air pumped through it for $30-60$ seconds, according to the quantity of specimens, to drive out the ether vapour. The degree of dryness was decided arbitrarily, drying being continued until no apparent signs of liquid were left on the surface of the body. When immersed in water most of the specimens sank to the bottom. The exact degree of drying is somewhat indefinite, but after a short training some homegeneity is obtained. The use of measured quantities of fluid gives this method an appreciable advantage over the filter-paper drying method.

As is well known, alcohol extracts a good many substances (Vinogradov, 1927 ), over $10 \%$ in weight. In order to evaluate the method and to find the amount (in weight) of substances extracted by the rapid flow of alcohol and ether in our device, the resulting liquor was analysed. It was found to contain a negligible quantity of extracted substances, fluctuating from $1-2 \%$. As compared to the filter-paper drying method the weight after " liquid " drying is somewhat smaller, but the range of fluctuation between separate weighings is clearly in favour of "liquid" drying.

2. Dry weight. The study of specimens by dry weight has many advantages over that by raw weight as it is evidently more accurate and supplies data of actual weight of the body-substance. The dry weight is thus a better characteristic of biomass and it should become the main unit in the determination of biomass.

The raw weight data depend chiefly on the quantity of water contained in the body, not on the quantity of substance of an organism, and the quantity of water in the body of different organisms is variable and depends on different conditions.

To find the dry weight a dessicator containing calcium chloride was used. After obtaining the raw weight the same organisms were placed on the grid of a dessicator on a weighed cover-slip. The material remained in the dessicator usually for two or three days, and weighing was repeated not less than three times at one-day intervals. If the last two weighings were equal the material was considered sufficiently dried and the counts were made.

The figures of dry weight thus obtained are not figures of constant dry weight. To obtain the latter the method must be considerably improved by drying in a high-temperature thermostat, or for a very long time. Yet this method gives figures, which, although not of absolute constant dry weight, are still constant to some degree, and fit for comparison, giving a 
much truer picture of the quantity of substance of an organism than does raw weight. The simplicity of operation, the little time needed, the portability and accessibility of the applied method and the comparative exactitude of the data obtained, tend to uphold dry weight as the best method for obtaining the biomass.

Both dry and raw weights were obtained on the Sartorius analytical balance.

3. The length measurements were made with a micrometer eyepiece. The total length was measured from the front edge of cephalothorax to the end of caudal furcæ, the furcal setæ being excluded.

\section{RESULTS.}

The results of weighing and measurement clearly show that both biomass and size of Calanus throughout the year are not constant but undergo changes, which so far as weight is concerned may be as great as twice their value.

The data show that the maximum of raw weight (Table I) was observed in May. Stage V (7th May), 0.7 mg. ; adult males (15th May), 1.13 mg. ; and females (15th and 22nd May), $1 \cdot 10 \mathrm{mg}$.

The minimum weights were for Stage V, 0.35 mg. (14th October and 13th November) ; adult males, $0.50 \mathrm{mg}$. (13th November) and females, $0.41 \mathrm{mg}$. (16th October). The maximum range of fluctuation was for Stage V, 0.35-0.70 mg. ; for adult males, $0 \cdot 50-1 \cdot 10 \mathrm{mg}$. ; for females, $0 \cdot 41-1 \cdot 10 \mathrm{mg}$.

The maximum dry weight for all stages (see Table II) occurred on 15th May: Stage V, 0.252 mg.; adult males, $0.259 \mathrm{mg}$.; and females, $0.256 \mathrm{mg}$. The minimum dry weights were for Stage $\mathrm{V}, 0.078 \mathrm{mg}$. (1st October) ; for adult males, $0 \cdot 100 \mathrm{mg}$. (16th October) ; and for females, $0 \cdot 100 \mathrm{mg}$. (16th October and 26th November).

\section{TABLE I.}

RaW Weight in Milligrams.

\begin{tabular}{|c|c|c|c|c|c|c|c|c|c|}
\hline Months. & \multicolumn{3}{|c|}{ February. } & \multicolumn{4}{|c|}{ March. } & \multicolumn{2}{|c|}{ April. } \\
\hline Dates. & 12 & 19 & 26 & 5 & & 2 & 27 & $11^{1}$ & 16 \\
\hline V & $0 \cdot 40$ & & & & & & & 0.44 & 0.48 \\
\hline VI ô & $0 \cdot 58$ & 0.61 & & & & & & & $0 \cdot 64$ \\
\hline VI 우 & $0 \cdot 69$ & $0 \cdot 58$ & $0 \cdot 56$ & $0 \cdot 7$ & & & $0 \cdot 58$ & $0 \cdot 64$ & $0 \cdot 89$ \\
\hline Months. & & May. & & & June. & & & & August. \\
\hline Dates. & 7 & 15 & 22 & 10 & 19 & 26 & 4 & 9 & 7 \\
\hline V & $0 \cdot 70$ & 0.68 & $0 \cdot 62$ & $0 \cdot 50$ & $0 \cdot 66$ & 0.43 & & $0 \cdot 57$ & 0.55 \\
\hline VI 0 . & $0 \cdot 85$ & $1 \cdot 13$ & $0 \cdot 90$ & $0 \cdot 69$ & $0 \cdot 74$ & & $0 \cdot 74$ & $0 \cdot 74$ & $0 \cdot 72$ \\
\hline VI 우 & 1.05 & $1 \cdot 10$ & $1 \cdot 10$ & $0 \cdot 84$ & $0 \cdot 93$ & $0 \cdot 80$ & $0 \cdot 86$ & $0 \cdot 88$ & 0.89 \\
\hline Months. & Sept & ber. & Octo & er. & Nov. & & Dece & aber. & \\
\hline Dates. & 3 & 16 & 14 & 16 & 13 & 3 & 10 & 17 & 22 \\
\hline V & $0 \cdot 61$ & $0 \cdot 39$ & $0 \cdot 35$ & $0 \cdot 40$ & $0 \cdot 35$ & 0.45 & $0 \cdot 39$ & $0 \cdot 40$ & $0 \cdot 39$ \\
\hline VI & $0 \cdot 83$ & & $0 \cdot 73$ & & $0 \cdot 50$ & 0.55 & $0 \cdot 59$ & $0 \cdot 55$ & $0 \cdot 53$ \\
\hline VI 우 & $0 \cdot 93$ & $0 \cdot 81$ & $0 \cdot 53$ & $0 \cdot 41$ & $0 \cdot 50$ & $0 \cdot 56$ & 0.62 & $0 \cdot 55$ & $0 \cdot 48$ \\
\hline
\end{tabular}




\section{TABLE II.}

\section{Dry Weight in Milligrams.}

\begin{tabular}{|c|c|c|c|c|c|c|c|c|c|c|}
\hline \multirow{3}{*}{$\begin{array}{l}\text { Months } \\
\text { Dates. } \\
\text { V } \\
\text { VI } \overrightarrow{0} \\
\text { VI \& }\end{array}$} & \multicolumn{3}{|c|}{ February. } & \multicolumn{2}{|c|}{ March. } & \multicolumn{2}{|c|}{ April. } & \multicolumn{3}{|c|}{ May. } \\
\hline & 12 & 19 & 26 & 5 & 27 & 11 & 16 & 7 & 15 & 22 \\
\hline & $0 \cdot 100$ & $\begin{array}{l}0 \cdot 132 \\
0 \cdot 128 \\
0 \cdot 122\end{array}$ & $0 \cdot 118$ & $0 \cdot 130$ & $0 \cdot 138$ & $0 \cdot 116$ & $\begin{array}{l}0 \cdot 119 \\
0 \cdot 158 \\
0 \cdot 175\end{array}$ & $\begin{array}{l}0 \cdot 24 \\
0 \cdot 25 \\
0 \cdot 25\end{array}$ & $\begin{array}{l}0 \cdot 252 \\
0 \cdot 259 \\
0 \cdot 256\end{array}$ & $\begin{array}{l}0 \cdot 216 \\
0 \cdot 250 \\
0 \cdot 252\end{array}$ \\
\hline \multicolumn{2}{|c|}{ Months. } & \multicolumn{2}{|r|}{ June. } & & \multicolumn{2}{|c|}{ July. } & \multirow{2}{*}{\multicolumn{2}{|c|}{$\underset{7}{\text { August. }}$}} & \multicolumn{2}{|c|}{ September. } \\
\hline \multirow{2}{*}{\multicolumn{2}{|c|}{$\begin{array}{c}\text { Dates. } \\
V\end{array}$}} & 10 & 19 & 26 & 4 & & & & & 16 \\
\hline & & $0 \cdot 150$ & $0 \cdot 190$ & $0 \cdot 166$ & $0 \cdot 184$ & $\begin{array}{c}9 \\
0 \cdot 196\end{array}$ & \multicolumn{2}{|c|}{$0 \cdot 196$} & $0 \cdot 134$ & $0 \cdot 139$ \\
\hline \multirow{2}{*}{\multicolumn{2}{|c|}{$\begin{array}{ll}\text { VI } & 0 \\
\text { VI } & 0\end{array}$}} & $0 \cdot 184$ & $0 \cdot$ & & $0 \cdot 200$ & $0 \cdot 174$ & \multicolumn{2}{|c|}{$0 \cdot 154$} & $0 \cdot 170$ & $\cdot 163$ \\
\hline & & $0 \cdot 186$ & $0 \cdot 224$ & $0 \cdot 172$ & $0 \cdot 172$ & $0 \cdot 214$ & \multicolumn{2}{|c|}{$0 \cdot 214$} & $0 \cdot 210$ & $0 \cdot 177$ \\
\hline \multicolumn{2}{|c|}{ Months. } & \multicolumn{3}{|c|}{ October. } & \multicolumn{2}{|c|}{ November. } & \multicolumn{4}{|c|}{ December. } \\
\hline Dat & & 1 & 14 & 16 & 13 & 26 & 3 & & 17 & 22 \\
\hline V & & $0 \cdot 078$ & $0 \cdot 116$ & $0 \cdot 112$ & $0 \cdot 128$ & $0 \cdot 116$ & $0 \cdot 106$ & $0 \cdot 128$ & & $0 \cdot 1$ \\
\hline$V I$ & & & & & $0 \cdot 110$ & & $0 \cdot 118$ & $0 \cdot 1$ & $0 \cdot 131$ & $0 \cdot 109$ \\
\hline VI & & $0 \cdot 134$ & $0 \cdot 110$ & $0 \cdot 100$ & $0 \cdot 124$ & $0 \cdot 100$ & $0 \cdot 110$ & $0 \cdot 126$ & $0 \cdot 120$ & $0 \cdot 141$ \\
\hline
\end{tabular}

\section{TABLE III.*}

Median Length $\left(Q_{2}\right)$ in Millimetres.

\begin{tabular}{|c|c|c|c|c|c|c|c|c|c|}
\hline Months. & \multicolumn{3}{|c|}{ February. } & \multicolumn{3}{|c|}{ March. } & \multicolumn{3}{|c|}{ April. } \\
\hline Dates. & 12 & 19 & 26 & 5 & 12 & 27 & 11 & 16 & 24 \\
\hline V & & $2 \cdot 72$ & & & & & $2 \cdot 89$ & $2 \cdot 98$ & \\
\hline VI $\hat{o}$ & $3 \cdot 01$ & $3 \cdot 02$ & & & & & $3 \cdot 30$ & $3 \cdot 27$ & \\
\hline VI & $2 \cdot 98$ & $2 \cdot 98$ & $2 \cdot 97$ & $3 \cdot 00$ & 2.96 & $2 \cdot 98$ & 3.07 & $3 \cdot 40$ & $3 \cdot 53$ \\
\hline Months. & & May & & & June. & & & & August. \\
\hline Dates. & 7 & 15 & 22 & 10 & 19 & 26 & 4 & 9 & 7 \\
\hline V & $3 \cdot 15$ & $3 \cdot 09$ & $2 \cdot 96$ & $2 \cdot 88$ & $2 \cdot 86$ & $2 \cdot 75$ & $2 \cdot 86$ & $2 \cdot 81$ & $2 \cdot 84$ \\
\hline VI 0 & $3 \cdot 54$ & $3 \cdot 59$ & $3 \cdot 52$ & $3 \cdot 30$ & $3 \cdot 30$ & & $3 \cdot 20$ & $3 \cdot 14$ & $3 \cdot 19$ \\
\hline VI 9 & 3.57 & 3.58 & $3 \cdot 61$ & $3 \cdot 37$ & $3 \cdot 37$ & $3 \cdot 27$ & $3 \cdot 24$ & $3 \cdot 25$ & $3 \cdot 30$ \\
\hline
\end{tabular}

\begin{tabular}{ccccccc|c|c|c|c|c|} 
Months. & \multicolumn{3}{c}{ September. } & \multicolumn{3}{c}{ October. } & \multicolumn{4}{c}{ November. } & \multicolumn{4}{c}{ December. } \\
Dates. & 3 & 16 & 1 & 14 & 16 & 13 & 26 & 3 & 10 & 17 & 22 \\
V & $2 \cdot 85$ & $2 \cdot 75$ & $2 \cdot 67$ & $2 \cdot 61$ & $2 \cdot 69$ & $2 \cdot 74$ & $2 \cdot 67$ & $2 \cdot 56$ & $2 \cdot 70$ & $2 \cdot 63$ & $2 \cdot 75$ \\
VI $\hat{\jmath}$ & $3 \cdot 24$ & $3 \cdot 14$ & $2 \cdot 95$ & $2 \cdot 80$ & $2 \cdot 84$ & $2 \cdot 90$ & $2 \cdot 85$ & $2 \cdot 98$ & $3 \cdot 09$ & $3 \cdot 01$ & $2 \cdot 99$ \\
VI $\hat{q}$ & $3 \cdot 38$ & $3 \cdot 24$ & & $2 \cdot 93$ & $2 \cdot 83$ & $2 \cdot 90$ & $2 \cdot 84$ & $2 \cdot 94$ & $2 \cdot 87$ & $2 \cdot 90$ & $2 \cdot 85$
\end{tabular}

From the measurements for Stages V and VI males and females were calculated the quantities $Q_{1}, Q_{2}$, and $Q_{3}, Q_{2}$ being the median size (see Tables III and V, and Fig. 3).

Stage IV was very scarce owing to the large-meshed net employed. Measurements gave the following results : April 11th, $2 \cdot 28 \mathrm{~mm}$. and 16th $2 \cdot 07 \mathrm{~mm}$.; May 7th, $2 \cdot 39 \mathrm{~mm}$.; June 10 th, $2 \cdot 10 \mathrm{~mm}$.; July 4th, $2 \cdot 10 \mathrm{~mm}$

* In the table are not included data of days when quantity of sampled material was too small to allow computation of average size $\left(Q_{2}\right)$. 
and 9 th, $2.13 \mathrm{~mm}$; September 16th, $2 \cdot 15 \mathrm{~mm}$. and $24 \mathrm{th}, 2 \cdot 20 \mathrm{~mm}$.; October 1st, $2.06 \mathrm{~mm}$. and 14th, $2 \cdot 11 \mathrm{~mm}$.

The maximum average length of the body occurred in May : Stage IV, $2.39 \mathrm{~mm}$. ; Stage V, $3.15 \mathrm{~mm}$. ; Stage VI males, $3.59 \mathrm{~mm}$; and Stage VI females, $3.61 \mathrm{~mm}$. The minimum average size occurred in October: Stage IV, 2.06 mm.; V, $2.61 \mathrm{~mm}$. VI males, $2.80 \mathrm{~mm}$. I females, $2.83 \mathrm{~mm}$.

In spite of the great changes of biomass and size during the year we see that for certain periods (see Figs. 2, 3, and 4) both biomass and size remain nearly constant. Three such seasons may be observed :

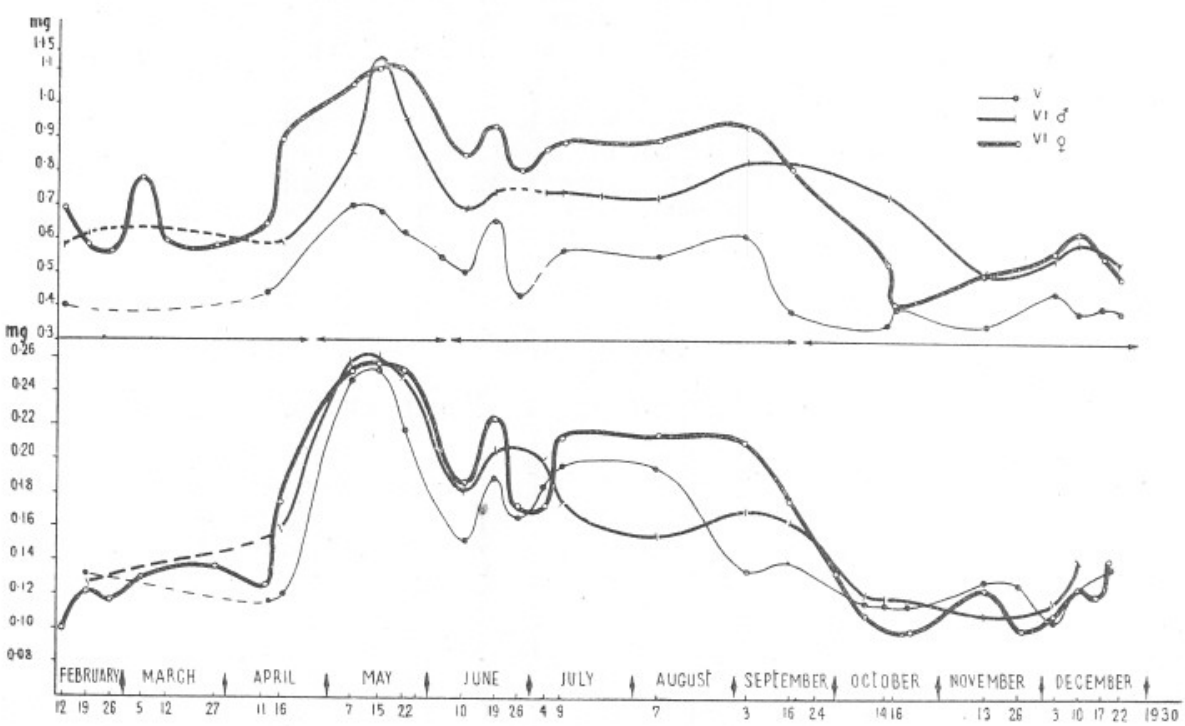

FIG. 2.- Seasonal changes of biomass in Calanus finmarchicus (copepodite Stages V, VI males and females) in the Plymouth area in 1930.

Upper part of the graph-curves for variations in average raw weight. Lower part of the graph-curves for variations of average dry weight. Horizontal line with arrows-period of predominance of a given generation.

The first season- " autumn-winter "-from end of September to middle of April ; the second season-" spring "-from end of April to June; the third-" summer "- from June to middle of September. As may be seen the seasons differ greatly in duration; and do not coincide with calendar seasons. But yet they are well differentiated in the biomass and size of Calanus. Small fluctuations in the curves during each season are possibly due to faulty methods in preparing and sampling of material.*

* Marshall (1933) has since shown that this may possibly be due to differences in size between the first and last born in any generation, the former being slightly larger than the latter. 
The length of the season is given in Figure 2 by horizontal lines. Our seasons may also be well characterized from the hydrographic view-point (Harvey, 1930) especially according to temperature. The "autumnwinter" season is characterized by homogeneousness of temperature from surface to bottom, the temperature value decreasing from month to month. Towards the end of the "spring " season a discrepancy appears between surface and bottom temperature, that of the surface getting warmer. The "summer" season is characterized by a marked stratification of temperatures and a strong warming of the whole mass of water,

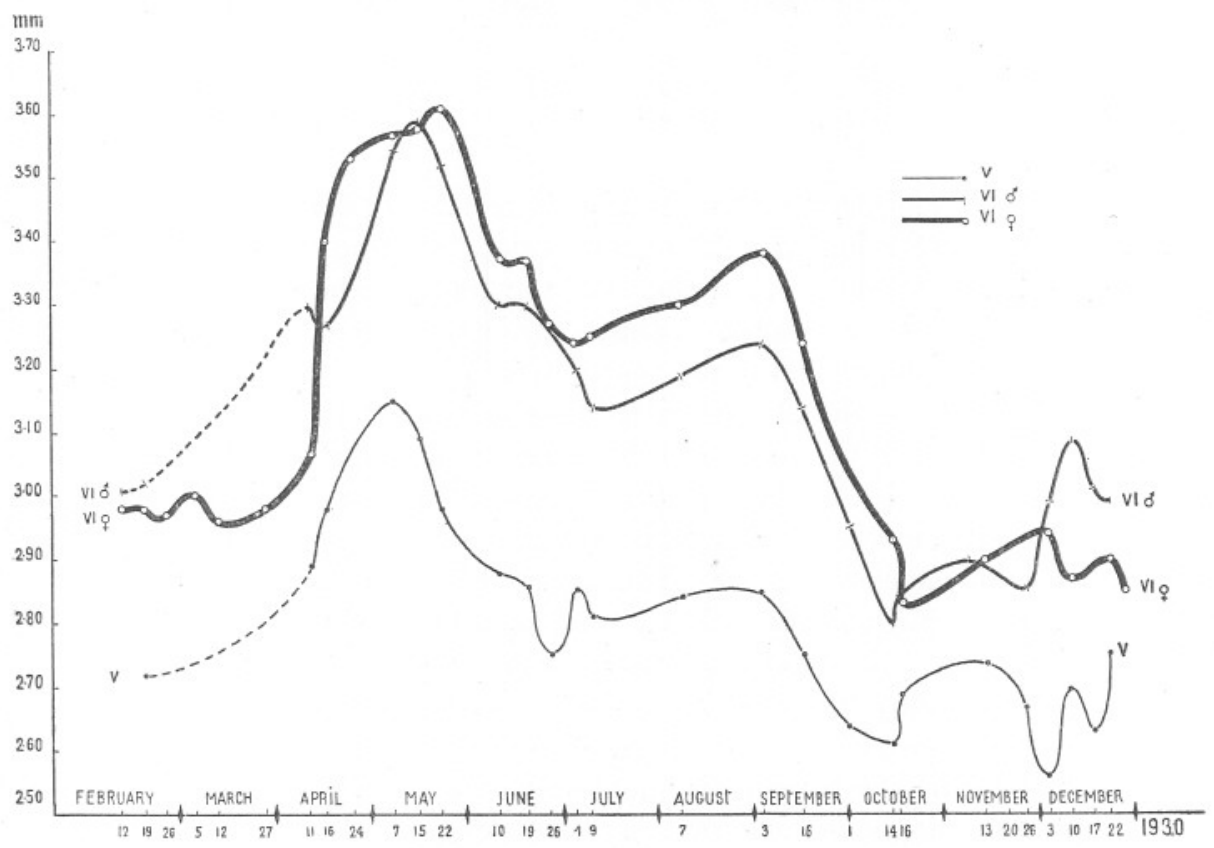

FIG. 3.- Seasonal changes in average size $\left(Q_{2}\right)$ of Calanus finmarchicus (copepodite Stages V, VI males and females) in the Plymouth area in 1930.

especially of the surface layers, the warmest time being towards the end of August and the bottom water attaining its maximum in September.

The salinity in the Plymouth area is subject only to slight fluctuations, its value being about $35^{\circ} \%$. The main source of the water supplied to the English Channel is the Atlantic. In the course of the year the main current of the English Channel is unstable in strength and partly in direction.

To characterize our seasons by biomass and size I have summed up data of Tables I, II, and III. In this way I obtained the following average values for biomass and size (Table IV) : 


\section{TABLE IV.}

\begin{tabular}{|c|c|c|c|c|c|c|}
\hline & & & Seasons. & & & Ratio of \\
\hline & & $\begin{array}{l}\text { Autumn, } \\
\text { Winter. }\end{array}$ & Spring. & Summer. & average. & $\begin{array}{l}\text { Autumn- } \\
\text { Winter. }\end{array}$ \\
\hline Raw & V & $0 \cdot 40$ & $0 \cdot 67$ & 0.53 & 0.53 & $1 \cdot 7$ \\
\hline weight & VI males & $0 \cdot 59$ & $0 \cdot 98$ & $0 \cdot 74$ & $0 \cdot 77$ & $1 \cdot 66$ \\
\hline mg. & VI females & $0 \cdot 60$ & $1 \cdot 08$ & $0 \cdot 87$ & 0.85 & $1 \cdot 8$ \\
\hline Dry & V & $0 \cdot 117$ & $0 \cdot 239$ & $0 \cdot 169$ & $0 \cdot 174$ & $2 \cdot 04$ \\
\hline weight & VI males & $0 \cdot 124$ & $0 \cdot 255$ & $0 \cdot 1$ & $0 \cdot 186$ & $2 \cdot 06$ \\
\hline mg. & VI females & 0.123 & $0 \cdot 254$ & $0 \cdot 196$ & $0 \cdot 191$ & $2 \cdot 06$ \\
\hline Avera & V & $2 \cdot 72$ & $3 \cdot 07$ & $2 \cdot 82$ & $2 \cdot 87$ & $1 \cdot 13$ \\
\hline size $\mathrm{mm}$. & VI male & $3 \cdot 00$ & $3 \cdot 57$ & $3 \cdot 22$ & $3 \cdot 26$ & $1 \cdot 19$ \\
\hline & VI females & $2 \cdot 96$ & $3 \cdot 57$ & $3 \cdot 30$ & $3 \cdot 28$ & $1 \cdot 21$ \\
\hline
\end{tabular}

Stage IV, which was very scarce, is not included in this table. The table shows that the minimum of biomass in the "autumn-winter" season is about as much smaller than the yearly average as the maximum of the "spring" season is greater. Values characteristic for "summer" forms are approximately equal to the yearly average.

The picture of the change in biomass and size during the year is as follows : Early in the year (from February to mid-April) the biomass and size are small. In April the picture begins to alter and in the material of April 16th occur big forms (see Fig. 4) and we observe a decided rise of the average for biomass and size. The big organisms prevail from the end of April and throughout May, the average value of biomass and size being at its maximum, which is characteristic for our " spring " season. From the end of May (May 22nd) begins a decrease in biomass and size, slight for adults and considerable for Stage $V$, continuing to the first decade of June. During the subsequent months, to the middle of September, the values of biomass and size remain stable, which is characteristic for our "summer" season. From the middle of September for adults, and the end of August for Stage V, biomass and size begin to decrease, the values reaching their lowest level in October and slightly rising again in the subsequent months, but still being very low and deviating greatly from those of the "spring" and "summer" seasons, which is characteristic for the " autumn-winter" season, from end of September to the middle of April.

August and September are intermediate months (see Fig. 4) containing forms, characteristic for different "adjacent" seasons, some organisms gradually replacing others in the course of the month. Evidently the same may be expected in June, but here the replacing of " spring " organisms by "summer" ones is much more rapid and does not show clearly in our material. 


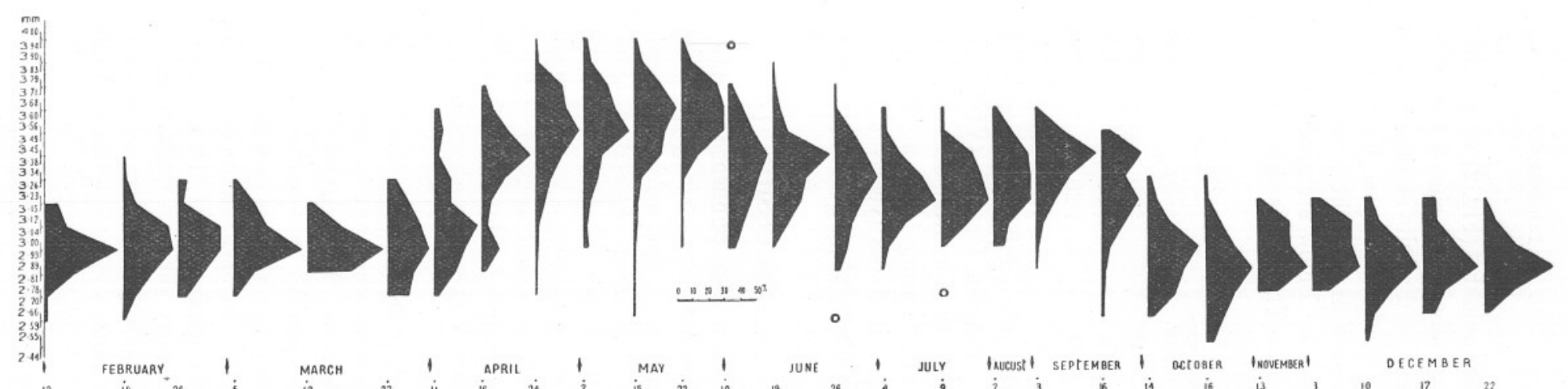

Fig. 4.- Seasonal changes in the percentage size distribution of Calanus finmarchicus (Stage VI females) in the Plymouth area in 1930. 
In the curves for "dry weight" (Fig. 2) we see the stage-curves following one another very closely. This shows that the difference in "raw weight " between Stage V and adults is due to the difference in quantity of water in specimens of these two stages. Calculation has shown that the surplus of raw weight over dry weight is not constant throughout the year or for different stages. Below are given data showing the ratio of raw weight to dry weight. (The figures show how many times raw weight is greater than dry weight.)

$\begin{array}{ccccc}\text { Stages. } & \begin{array}{c}\text { Sutumn- } \\ \text { Winter. }\end{array} & \begin{array}{c}\text { Seasons. } \\ \text { Spring. }\end{array} & \begin{array}{c}\text { Searly } \\ \text { average. }\end{array} \\ \text { V } & 3 \cdot 40 & 2 \cdot 80 & 3 \cdot 10 & 3 \cdot 10 \\ \text { VI } \hat{\circ} & 4 \cdot 75 & 3 \cdot 80 & 4 \cdot 10 & 4 \cdot 22 \\ \text { VI }+ \text { 우 } & 4 \cdot 90 & 4 \cdot 20 & 4 \cdot 40 & 4 \cdot 50\end{array}$

These figures show that the adults contain more water than Stage V, the greatest quantity being in females (VI +), and that during the "autumn-winter" season the quantity of water is at its maximum, the minimum occurring in the "spring " season. If the quantity of water be expressed in percentages, it shows (yearly average data) that Stage $V$ contains $65 \%$ of water ; adults VI males, $76 \%$; and VI females, $78 \%$.

\section{DISCUSSION.}

No exhaustive data have been published on the biology of Calanus finmarchicus in the Plymouth area. Gough (1905), Lebour (1917), and others record the presence of $C$. finmarchicus all through the year and its predominance (Lebour, 1917) from the end of April to the beginning of November. Russell (1928) was the first to give quantitative data for Calanus in the Plymouth area (Stage $\mathrm{V}$ and adults, males and females) for a period from April 9th to September 22nd, 1926. His results show that the adults exhibit two maxima in abundance, the first in May-June, the second in August. Stage $\mathrm{V}$ shows an alternating decrease and increase in quantity each month.

Russell (1933, Table I, p. 76) gives the total numbers of Calanus in the half-hour oblique hauls from which my material was obtained, and these results are plotted in Figure 5. Early in the year $C$. finmarchicus was very scarce. In March Stages $\mathrm{V}$ and $\mathrm{VI}_{\widehat{o}} \widehat{ }$ were entirely lacking. At the beginning of April the quantity began to increase rapidly showing enormous figures to the end of the month. In May the quantity increased still further, reaching on May 7 th the maximum of 318,450 specimens in a half-hour haul. In June the quantity shows a marked fall, still remaining at a comparatively high level (about 1000 specimens for a half-hour haul) and keeps stable during the whole summer to the beginning of August. From 
the end of September the number begins to decrease rapidly (about 100 specimens per haul) becoming quite small in the middle of October and remaining so through all the "autumn-winter" period. There are

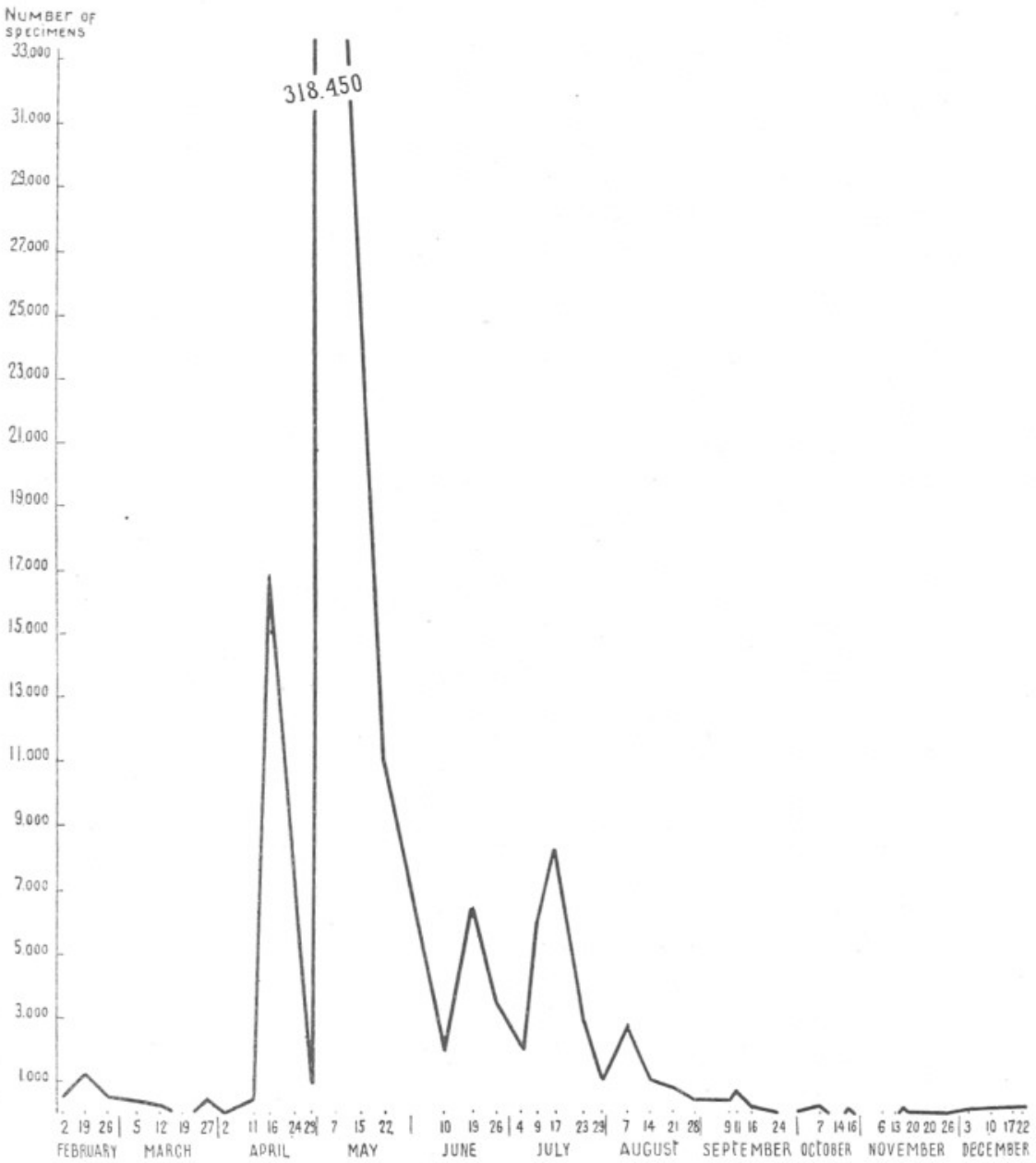

FIG. 5.- Seasonal changes of total number of Calanus finmarchicus (copepodite Stages IV, V, VI-males and females) in the Plymouth area in 1930.

Number of specimens caught during a half-hour oblique haul with a 2-metre stramin ring-trawl. Mostly composed of Stage VI females.

occasional marked decreases in quantity, e.g. at the end of April, or in summer, but the general trend of the curve remains constant.

The same picture is given by other authors for different parts of the North Sea and the adjoining areas: Paulsen (1906), Damas (1905), 
Gran (1902), Marshall (1924), Farran (1920, 1927), Johnstone, Scott, and Chadwick (1924), Runström (1932), and others.

The observed times of reproduction of Calanus finmarchicus in different parts of the North-European seas are as follows :* Gran (1902) states that the period of reproduction is April-May for the North-Western coast of Norway; Damas (1905), June for the Norwegian Sea; May and June for the Faroe Islands. Paulsen (1905), from the end of March up to June for Southern Iceland. Damas and Koefoed (1907), end of June for Norway and Spitzbergen. With (1916), June for Danish current; May, for Southern Iceland; June and July, for Western Greenland, and the end of June for Eastern Greenland. Johnstone, Scott, and Chadwick (1924) assign the time from June to August and from September to October as the periods of reproduction for the Irish Sea in the area of Port Erin, whilst Farran (1927) considers April and May as the main period of reproduction for the given area.

The occurrence of both males and females of $C$. finmarchicus all the year round in these regions gives rise to the suggestion that there may be several periods of reproduction and hence several generations in the course of a year.

Paulsen (1905) suggests two periods of reproduction for Iceland area : early spring and end of summer. Ruud (1929) points out the occurrence of a great number of nauplii in the Möre area in March-April and JuneJuly, indicating that there may be two periods of reproduction in this area, in spring and in summer; the suggested time of spawning for the first period is February-March, for the second, May-June.

In Runström's (1932) tables on page 58-59 we see that the great quantities of $C$. finmarchicus, occurring from March to September, are interrupted by smaller quantities in July. This may be explained by the existence of two periods of reproduction.

Russell (1928) on the basis of measurements states that the great number of $C$. finmarchicus, appearing at the end of April, were hatched in March. This brood is marked by its large size and is termed by the author as "large" brood. This "large" brood is short-living and in the course of May reproduces individuals of a smaller size, "small " brood, and soon dies off. Throughout the summer months, July and August and presumably in September, intermittent spawning occurs, resulting in a new generation, which tides over the winter months to spawn early in the next spring and reproduce once more a brood of large individuals. Females carrying spermatophores occur throughout the year ; in April the number of spermatophore-carrying females is greater than in the following months of May and beginning of June; then it rises again, reaching the April value in August.

* Most authors have no yearly material available, which is a drawback. 
Thus we may consider that Russell records three periods of reproduction throughout the year, the first period being March-April; the second, May; and third, July-August.

In other regions, too, several periods of reproduction are recorded. Bigelow (1926) records two periods of reproduction for the area of the Gulf of Maine-spring (May) and autumn (September). The first period gives rise to abundant masses of $C$. finmarchicus in spring and summer months; the second period gives smaller quantities, but constantly occurring in the winter months and reproducing again great quantities in spring.

Farran (1927) finds that in the area south of Ireland the young of the previous year become adult in January, February, and March, and that there is a big outburst of reproduction in March-April, reproduction then going on irregularly throughout the rest of the summer.

We have the right to presume the existence of only one generation for Arctic seas, where males occur in a definite short period of time, being quite rare in the plankton (Bogorov, 1932) ; whereas in those regions, where both sexes occur throughout the year, we have full reason to presume the existence of several periods of reproduction.

My Plymouth material, though not supplying data on young stages and on the presence of spermatophore-bearing females, leads me, nevertheless, to conclusions approaching those of Russell ; I endeavoured to complete these data with winter material and to complete the picture of yearly changes in the biomass.

Taking the period of development of Calanus from egg to adult as averaging two months (Lebour, 1916), the rate of the process being different at different seasons, we may presume that the appearance of great masses of Calanus at the end of April and especially in May is due to their reproduction early in the year. These individuals differ appreciably in size and weight from those occurring in winter catches (see Fig. 4). They are considerably greater and heavier; VI females, size, $3.57 \mathrm{~mm}$. ; raw weight, 1.08 mg. ; dry weight, $0.254 \mathrm{mg}$. (see Table IV), whereas the size and weight of the "autumn-winter" individuals, having produced the above mentioned is : VI females, size, $2.96 \mathrm{~mm}$.; raw weight, $0.60 \mathrm{mg}$. ; and dry weight, $0 \cdot 123 \mathrm{mg}$. The generation of big individuals predominates in the adult stage for a very short time, from end of April to beginning of June, after which, as Figure 4 shows, it disappears, giving place to smaller and lighter individuals, resulting from a generation, produced from big individuals of the end of May. This new generation predominates from June to the beginning of September and is characterized by its size: VI females, $3.30 \mathrm{~mm}$.; raw weight, $0.87 \mathrm{mg}$., and dry weight, $0 \cdot 196 \mathrm{mg}$. In September occurs a rapid disappearance of the generation in question, and a replacement by smaller individuals. The latter generation 
results from intermittent reproduction throughout the summer season, as pointed out by Russell.

It may be supposed that the end of August and beginning of September is the last period of summer reproduction, the resulting generation tiding over the autumn-winter period. Such intermittent reproduction makes both biomass and size unstable in the autumn and winter periods. However both biomass and size show a slight marked tendency to increase in the course of the period. This is clearly shown by changes in the monthly average.

Stage.

Raw weight.

Dry weight.

Size.

Months. Oct. Nov. Dec. Feb. Mar. Oct. Nov. Dec. Feb. Mar. Oct. Nov. Dec. Feb. Mar.

\begin{tabular}{|c|c|c|c|c|c|c|c|c|c|c|c|c|c|}
\hline$\nabla$ & $\begin{array}{ll}38 & 0 \cdot 35\end{array}$ & $0 \cdot 41$ & $0 \cdot 40$ & & $0 \cdot 102$ & $0 \cdot 122$ & $0 \cdot 124$ & $0 \cdot 132$ & & $2 \cdot 66$ & $2 \cdot 71$ & $2 \cdot 66$ & $2 \cdot 72$ \\
\hline & $0.73 \quad 0.50$ & 0.56 & $0 \cdot 60$ & & 110 & $0 \cdot 110$ & $0 \cdot 125$ & $0 \cdot 128$ & & 86 & $2 \cdot 88$ & $3 \cdot 02$ & .02 \\
\hline & $\begin{array}{ll}47 & 0 \cdot 50\end{array}$ & 0.55 & $0 \cdot 61$ & $0 \cdot 65$ & $0 \cdot 115$ & $0 \cdot 112$ & $0 \cdot 124$ & $0 \cdot 113$ & $0 \cdot 134$ & 2.88 & $2 \cdot 87$ & $2 \cdot 89$ & $2 \cdot 98$ \\
\hline
\end{tabular}

Hence biomass and size in February and March are greater than in October, November, and December. This is probably due to the dyingoff of the early born individuals; Stage $\mathrm{V}$ being the source from which adults are drawn (recorded by Farran, 1927) up to the end of February, at which time all the Stage V pass into adults. This coincides with the disappearance of adult males, and supports the suggestion that fertilization had taken place not long before, after which appears a new generation. Several months may elapse before the laying of eggs and hatching of nauplii as pointed out by Farran (1927).

It is worthy of notice that during the " autumn-winter" season males are much more abundant than females, which is just the reverse in other periods.

We would be justified in considering the $C$. finmarchicus of different sizes occurring at different seasons as separate generations if we had proof enough that they actually originated from one another, and that the waters of the region investigated were of the same origin. To decide the first question we need information on the occurrence of the different stages of development throughout the year (viz. eggs, nauplii, and all copepodid stages). Unfortunately I have no available material of that kind, but the literature data, especially those supplied by Russell (1928) and the hydrographical conditions of the waters of the English Channel, strongly support the opinion that several generations may occur here, the waters being from a homogeneous source, namely, the Atlantic.

For lack of material I can give no definite answer to the essential question, whether the Calanus in the Plymouth area are constant inhabitants or whether they are brought here by water currents. But even if these masses of Calanus are brought from another region, our considerations hold true and we have only to make allowance for the time of 
migration of these masses and for the areas of reproduction of Calanus, from which the main source of supply in the Plymouth region is drawn.

As a result of the present investigation we have the following " generations," which I have named according to the seasons in which they predominate.

The "spring" generation - resulting from reproduction in FebruaryMarch. Adults predominate in the plankton for about a month and a half (from end of April to May). Value of biomass and size is greatest compared to that of other seasons (Table IV, Figs. 2 and 4).

The "summer" generation - resulting from May reproduction. Adults prevail for about $3 \frac{1}{2}$ months from June to mid-September. In biomass and size they are smaller than those of the spring generation.

The "autumn-winter" generation-resulting from intermittent reproduction during the summer months from June to August. The adults prevail during eight months from end of September to mid-April. In biomass and size this generation is the smallest.

What are the causes of seasonal changes of biomass and size? In Figure 6 are given changes in temperature (from Russell, 1932) and in the size of Calanus for the year 1930. The salinity in the Plymouth area is not subject to any appreciable changes in the course of the year; the source of water supplied into the Channel remains the same, namely the Atlantic.

While it must be realized that many factors influence biological phenomenon it is evident that temperature is of great importance, reflecting as it does, other environmental changes.

Considering the two-months period, which Calanus takes for developing from the egg to the adult, we see that the "spring " Calanus hatched and developed in cold winter water at the temperature of $8-9^{\circ}$; the "summer" Calanus grew up in the warmer water of spring and early summer at 10.5 $-14.5^{\circ}$; and the "autumn-winter" Calanus developed in still warmer water of the end of summer at $15-16^{\circ} \mathrm{C}$. Plotting on the same graph (Fig. 6) the curve of change of biomass, characteristic for the given season (Table IV) and that of temperature conditions characteristic for the moment of reproduction and beginning of development, i.e. two months previously, we obtain evidence of the interrelation between temperature conditions at the beginning of development and the value of biomass and size of the adults. We see that big organisms with large biomass and size are generated under low temperature conditions and vice versa. If we follow the changes in biomass and size during the "autumnwinter " season we observe, as stated above (page 600), that the value of both increases from month to month, the temperature falling respectively. Again we see here the same interrelation, i.e. falling of temperature producing increase in biomass and size. 
In contrast to the above we have to deal here with the long-living Stage V, which gradually passes into the adult stage (as recorded by Farran, 1927). Resulting from such lengthy development under conditions of continually decreasing temperature we obtain, in FebruaryMarch, organisms marked by their greater size in comparison with individuals of the same generation, which have passed a shorter cycle of development and reached the adult stage in October-December. Thus the influence of temperature, which affects later stages of development, is noticeable in the size of adult organisms just as much as if it had occurred in earlier periods of growth.

Investigations on the yearly changes in size of marine and fresh-water

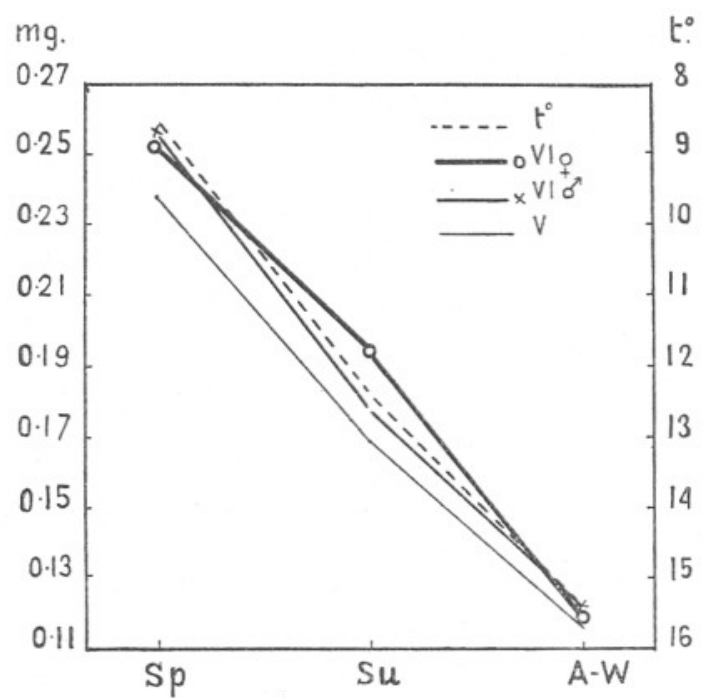

FIG. 6.-Average biomass of a generation of a given season; temperature at time of hatching and beginning of development of a given generation. Sp. $=$ Spring $;$ Su. $=$ Summer $;$ A. $-W .=$ Autumn-Winter.

copepods have been made by a number of workers; amongst these the following may be quoted, Adler and Jespersen (1920), on Calanus, Pseudocalanus, and Temora ; Gran (1902) on Calanus ; Rzoska (1927) on Cyclops strenuus; Störmer (1929); Ruud (1929); Gardiner (1933); and Russell (1928) on Calanus.

Comparing our results of 1930 with those of Russell (1928) for 1926 we plotted a graph (Fig. 7) where the thick line shows our results and the thin one those of Russell. We see that in the main 1930 results are characterized by lower temperature and greater size while in 1926 we observe the reverse phenomenon. The graph as a whole, as well as in detail, is very convincing. The "spring " Calanus of May 1930 is larger than that of 
1926, temperature conditions at the time of hatching and development (February-March) in 1930 being colder than in 1926. In June and beginning of July the size-curves of 1930 and 1926 follow one another very closely, showing even a smaller size in 1930, but the temperature conditions of May, when the generation in question was developing, were warmer in 1930 than in 1926. Further, the summer of 1930 was colder than in 1926, resulting in the greater size of Calanus of 1930. Finally, in early autumn the temperatures of 1930 and 1926 become similar, which is reflected in the close coincidence of the curves.

It is interesting that the size-curve of summer 1930 is repeated as it

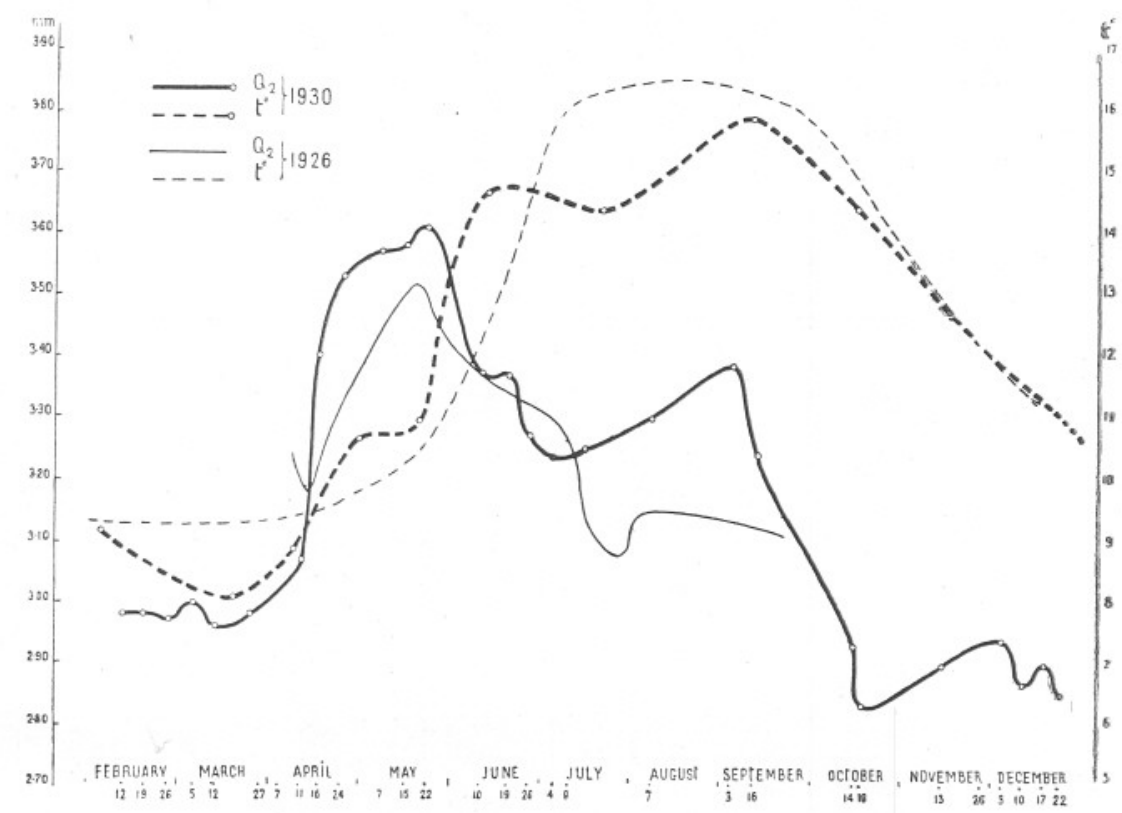

FIG. 7.-Comparison of seasonal changes of size of Calanus finmarchicus (Stage VI females) and of temperature in the years 1930 and 1926 in the Plymouth area.

Thick line, 1930 ; thin line, 1926 ; continuous line, size of females ; broken line, temperature.

were by the temperature curve. Thus we see that the forms in September are larger than those in July. This discrepancy with the basic data is not essential as far as biomass (Fig. 2) is concerned, and the sizes of 1926 Calanus do not exhibit such a picture. It is worthy of notice that the discrepancy between the sizes of 1930 and those of 1926 at the same time is as great as the difference in temperatures of June and early July, which fact, considering the time of development of $C$. finmarchicus, is another proof of the definite dependence between temperature and size of organisms. 
In order to elicit the correlation of temperature and size of organism I drew a correlation table (Fig. 8), (a) for comparing the biomass and length of organism and the temperature of the medium (Nos. 1 and 3), this

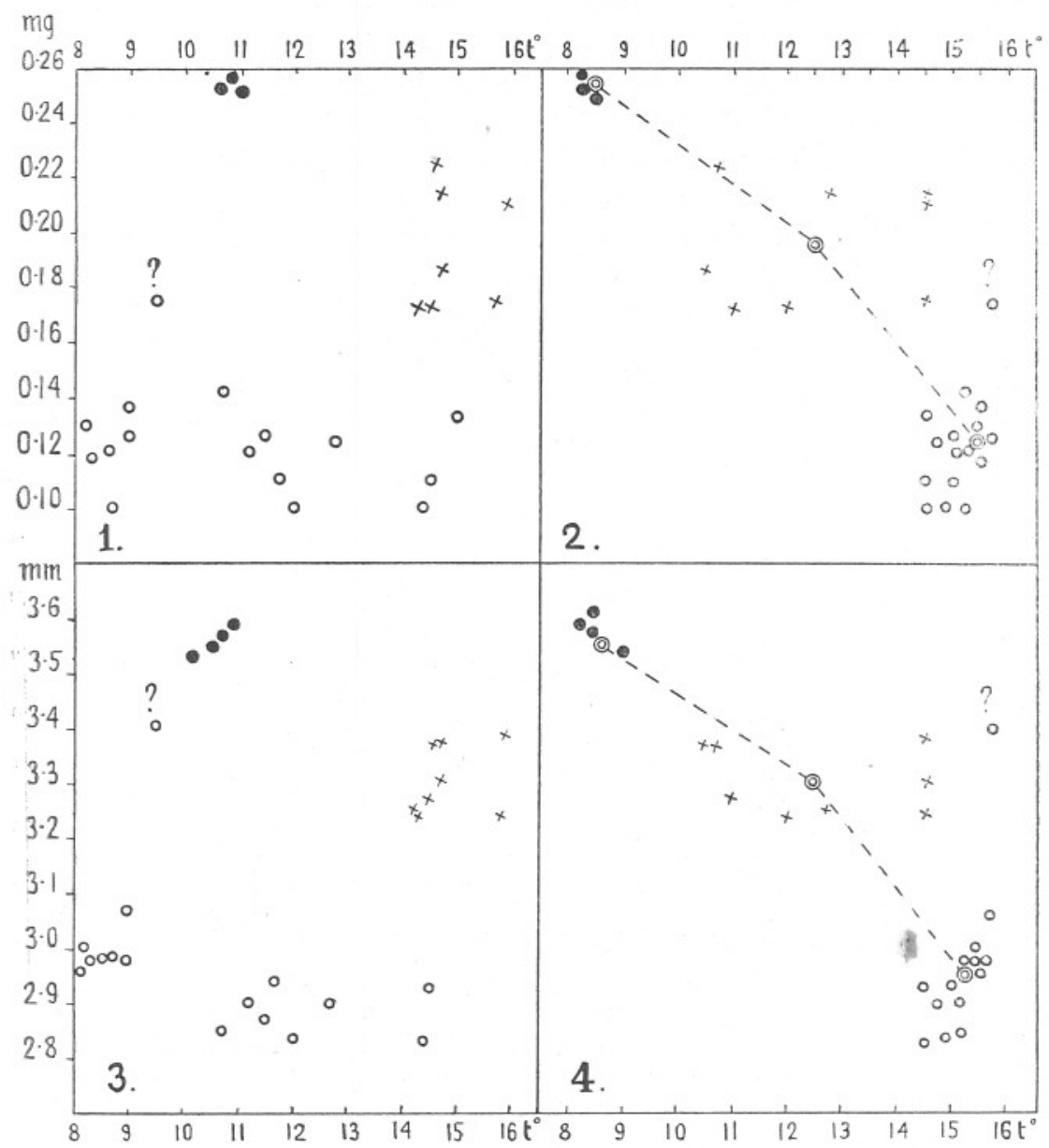

Fig. 8.-Correlation table. Comparison of size and biomass of Calanus finmarchicus (females) with temperature.

Nos. 1 and 3-Comparison of biomass (dry weight) and size with temperature of medium. Nos. 2 and 4 Comparison of biomass and size with temperature at time of hatching of given generations.* ( $\bullet=$ Spring generation ; $\times=$ Summer generation : $\mathrm{O}=$ Autumn-Winter generation.)

being the static moment; and $(b)$ for comparing the temperature of the period of reproduction with the biomass and length of the resulting generation (Nos. 2 and 4), this being the dynamic moment. In order to

* In Nos. 2 and 4, average values of a given generation are connected by a straight line. 
facilitate reading I have put different signs for different generations. The correlation table shows clearly that firstly (Nos. 1 and 3) small and large organisms occur at all possible temperatures, and secondly (Nos. 2 and 4) all points are strictly within definite temperature limits; if a line be drawn from small to large organisms it will show that low temperature throughout the period of development is the greatest stimulant to growth and vice versa.

The graph shows also that in studying the correlation of temperature and size the question is to be regarded from the point of view of dynamics.

A number of investigations on origin of forms in Copepoda show that different geographic-hydrological areas are inhabited by different species and more minute taxonomic subdivisions, low temperature areas being characterized by species and forms of larger size, whereas the warm tropical waters are inhabited by small-sized forms. In a series of papers Steuer (1923 and 1931) has shown on the genus Acartia, Pleuromamma, and Rhincalanus that, for example, the large-sized species Rhincalanus gigas is abundant in the cold waters of the Antarctic. The mediumsized $R$. nasutus is widely known in all oceans, but in the colder waters. The small-sized $R$. cornutus is met with in the warm surface water of the Atlantic and Indian Oceans.

By comparing the size of $C$. finmarchicus in the Barents Sea with that of this species in the Plymouth area I found (1933) that the former was much larger. The temperature conditions of Barents Sea waters are much colder than those of the Plymouth area, which accounts for the difference in size of the Calanus.

Many of the above-mentioned authors-Adler and Jespersen (1920), Ruud (1925), Störmer (1929), and others - give the same data. Later investigations in Barents Sea (Bogorov and Preobrajenskaya) have shown, that in different areas of the Barents Sea, which is heterogeneous in its hydrographical conditions, both biomass and size of $C$. finmarchicus vary also, being larger in cold-water than in warm-water regions.

It would be interesting to make an attempt to find the interdependence between biomass of the plankton organism and the temperature differences.

The difference in temperature between the times of hatching of "spring" and "autumn-winter" generations of $C$. finmarchicus in the Plymouth area is about $8^{\circ}$. In biomass the "spring "Calanus are twice as large as the "autumn-winter" ones. The difference of temperature of the English Channel and the Barents Sea* is about $10^{\circ}$; average biomass in C. finmarchicus of the Barents Sea is about twice the value of

* In both cases we compare the temperature for time and locality of sampling of C. finmarchicus, hence our average data are not the averages for the whole English Channel or the Barents Sea. 
that of $C$. finmarchicus in the English Channel. But the comparison of the northern part of the Barents Sea with the southern one showed that $5^{\circ}$ difference in temperature brought forth a threefold difference in biomass. Hence the value of the difference in temperatures depends on its place on the temperature scale, the influence of smaller differences in temperatures, under lower temperatures having a greater effect than large differences at higher temperatures. This means that the size of an organism (biomass) is no simple function of one single factor, even if it be such an important one as temperature, and that there is in different cases the combined influence of various conditions, forming altogether the physico-chemical and biological complex of conditions of existence of the organism. It is quite evident, nevertheless, that temperature conditions are of paramount importance in this complex.

We stated above that the $C$. finmarchicus of the Barents Sea produces only one generation in the course of the year while that of Plymouth area gives three generations. Thus the Calanus of the Barents Sea lives longer than that of Plymouth area, its biomass also being respectively greater. This leads to the conclusion that organisms in cold-water regions have the advantage of greater biomass, whereas warm-water organisms can produce more generations. It is interesting to note that when summed up, the biomass of three generations of $C$. finmarchicus in the Plymouth area (adult females-2.55 mg. raw weight and $0.574 \mathrm{mg}$. dry weight) approximately equals the average biomass of Calanus in the Barents Sea (adult females $-2 \cdot 18 \mathrm{mg}$. raw weight, $0 \cdot 670 \mathrm{mg}$. dry weight).

These results lead up to the general problem of the. relations between temperature, development, and length of life, feeding and metabolism, and growth in size. Amongst others the following workers may be cited : Rzoska (1927) on Cyclops; Russell (1932) on Sagitta ; Mielck (1919, cited from Samojloff, 1926) on Arctic fishes ; Loeb (1910) ; and Adler and Jespersen (1920). No decisive answer, however, can be found until we know exactly the quantitative and qualitative variations in the food consumed throughout the year. The food of Calanus has been investigated by Marshall (1924), but in insufficient detail for our purpose. It is interesting that the spring and summer Calanus are reddish yellow with abundant fat inclusions, while the winter specimens are greenish white, and lacking fat inclusions or with very slight ones, presumably due to reduced winter nutrition. Samojloff (1926) has suggested a knowledge of the age to which fossil animals lived will help towards obtaining the temperature conditions of bygone times.

Before concluding I should like to emphasize one particular point I recorded above that the maximum number of specimens fell in with the maximum value of biomass and sizes in spring and vice versa, the minimum quantity occurring during the period of the minimum of biomass and size 
in autumn and winter. This is clearly seen from the details; thus in June (Figs. 2 and 5) we observe, as it were, a pulsation of quantity, reflected by a similar pulsation in biomass - greater biomass and greater number of individuals occurring simultaneously. I suppose this must be explained by the fact that conditions, favourable for the rise in biomass, are at the same time optimal ones for the development of great numbers of individuals. This result is of great biological importance, being contrary to the generally accepted view that the larger-sized organisms are more easily formed in regions with scarce population, where the density of life (number of individuals per definite volume) is smaller.

All the factors mentioned affect to some greater or smaller degree the size of an organism dependent on different combinations of life conditions and forming in their complex the essential problem of "organism and medium." In this complex of various conditions the temperature is the most important, biomass and size of organism being reversed in proportion to temperature conditions during the time of growth.

\section{SUMMARY.}

1. The present paper deals with changes of biomass and size of Calanus finmarchicus throughout the year, in the Plymouth area.

2. The material was supplied by regular oblique hauls during 1930 ; Stage $\mathrm{V}$ and adult males and females having been examined. Calanus finmarchicus occurred throughout the year reaching its maximum value in May, being abundant from the middle of April to the middle of September.

3. Methods. The study of the material was based on the determination of raw weight, dry weight, and length measurements. For determination of raw weight a special method was worked out consisting of "liquid" drying of the body surface with alcohol and ether flowing through a special device, air being pumped through eventually for driving away the ether vapour. This method supplies data more suitable for comparison than those obtained by filter-paper drying. Dry weight was determined after drying in a desiccator. The data of dry weight are more exact and reliable than those of raw weight; dry weight also gives a better idea of quantity of substance, i.e. biomass of the plankton organism. Raw weight depends chiefly on the quantity of water in the organism.

Total length of the body was determined.

4. In the course of the year both biomass and size vary appreciably, the size of an organism being, however, approximately constant for a given period of time. Three such seasons are adopted; the first- "spring" 
season-May; the second "summer" season-June, July, August, September ; and the third-“" autumn-winter "-from October to April.

5. These seasons are markedly differentiated in biomass and size, which are characteristic for each season (see Table IV): thus the maximum biomass for all stages occurs in the spring season, decreasing in the summer season and reaching then the yearly average. In the autumnwinter season we have the minimum biomass. Size varies similarly.

6. For the area under investigation we think it possible to specify three periods of reproduction, hence three generations of Calanus finmarchicus, named in respect to their time of living "spring," "summer," and " autumn-winter."

The length of life of each generation depends on the length of a given hydrological regime, a new generation growing up at the time of basic change in the regime, the old one dying off.

7. A definite relation is obvious between size of organism and hydrological conditions, the main factor being temperature, particularly during the period of development. Thus the large sized "spring" generation was hatched at $8-9^{\circ} \mathrm{C}$. of temperature; the smaller-sized "summer" generation at $10 \cdot 5^{\circ}-14 \cdot 5^{\circ} \mathrm{C}$.; the very smallest "autumn-winter" hatched at the warmest temperature of $15-16^{\circ}$ C. (see Figs. 7 and 9). We are justified in presuming that the size attained and the temperature conditions during development are inversely proportional.

8. Interrelation between temperature and size of Copepoda has been recorded by many authors, size being largest at low temperatures and vice versa. This phenomenon is widely known and used in comparisons of all kinds: geographical, regional, seasonal, vertical (from surface to bottom), sectional (crossing water with different temperature conditions), yearly (comparing years having different temperature conditions).

9. Generations differ from one another not only in size but in physiology (F. S. Russell).

10. Data of dry weight show that the body of adult females contains a greater percentage of water, the water-content varying with seasons, being at its minimum in spring and reaching the maximum in winter.

\section{REFERENCES.}

Adler, G., and Jespersen, P. 1920. Variations saisonnières chez quelques Copépodes planctoniques marins. Medd. fra Komm. Havunders. Série Plankton, Bd. II.

Apstein, C. 1896. Das Süsswasserplankton. 
Bigelow, H. B. 1926. Plankton of the Offshore Waters of the Gulf of Maine. Bull. Bureau Fisheries, Washington, Vol. XL, 1924, Doc. No. 968.

Bogorov, B. G. 1932. Material on the Biology of the Copepodes of the Barents and the White Sea. Bull. State Oceanographical Institute, U.S.S.R., No. 4.

Bogorov, B. G. 1933. Modifications in the biomass of Calanus finmarchicus in accordance with its age. Bull. State Oceanographical Institute, U.S.S.R., No. 8.

Bogorov, B. G., and Preobrajensky, E. N. The biomass at Plankton organisms of the Barents Sea. II, Copepoda (in press). Trans. State Oceanographical Institute, U.S.S.R.

Damas, D. 1905. Notes biologiques sur les Copepodes de la Mer Norvégienne. Public. de circonstance No. 22. Cons. perm. intern. pour l'expl. de la mer.

Damas, D., and Koefoed, E. 1907. Le Plankton de la Mer du Groenland. Duc d'Orleans Croisière Oceanogr. dans la Mer du Groenland en 1905-Résultats Scient.

Farran, G. P. 1920. On the local and seasonal distribution of the pelagic Copepoda of the South-West of Ireland. Publications de Circonstance, No. 73.

Farran, G. P. 1927. The Reproduction of Calanus finmarchicus off the South Coast of Ireland. Journal du Conseil. Int. Explor. Mer., Vol. II, No. 2.

Gardiner, A. C. 1933. Vertical Distribution in Calanus finmarchicus. Journ. Mar. Biol. Assoc., N.S., Vol. XVIII, No. 2.

Gough, L. H. 1905. Report on the Plankton of the English Channel in 1903. Internat. Investig. Mar. Biol. Assoc., Rep. I, 1902-3.

Gran, H. H. 1902. Das Plankton des norwegischen Nordmeeres von biologischen und hydrografischen Geschichtspunkten behandelt. Rep. on Norw. Fishery and Marine Investigations, Vol. II, No. 5.

Harvey, H. W. 1930. Hydrography of the Mouth of the English Channel, 1925-1928. Journ. Mar. Biol. Assoc., N.S., Vol. XVI, No. 3, p. 791 .

Hensen, V. 1887. Ueber die Bestimmung des Planktons oder des im Meere treibenden Materials an Pflanzen und Tieren. Bericht der Kom. z. wiss. Unters. d. deutschen Meere.

Jonstone, J., Scott, A., and Chadwick, H. C. 1924. The Marine Plankton. University Press, Liverpool. 
Loeb, G. 1910. Dynamics of living substance. Odessa.

Lebour, Marie V. 1916. Stages in the Life History of Calanus finmarchicus (Gunnerus), experimentally reared by Mr. L. R. Crawshay in the Plymouth Laboratory. Journ. Mar. Biol. Assoc., Vol. XI, No. 1.

Lebour, Marie V. 1917. The Microplankton of Plymouth Sound from the Region beyond the Breakwater. Journ. Mar. Biol. Assoc., Vol. XI, No. 2.

Marshall, Sheina. 1924. The Food of Calanus finmarchicus during 1923. Journ. Mar. Biol. Assoc., N.S., Vol. XIII, No. 2.

Paulsen, Ove. 1906. Studies on the Biology of Calanus finmarchicus in the Waters round Iceland. Med. fra Kom. for. Havund., Serie Plankton, Bd. II, No. 4.

Russeld, F. S. 1928. The Vertical Distribution of Marine Macroplankton. VII. Observation on the Behaviour of Calanus finmarchicus. Journ. Mar. Biol. Assoc., N.S., Vol. XV, No. 2.

Russelt, F. S. 1932. On the Biology of Sagitta. The Breeding and Growth of Sagitta elegans Verill in the Plymouth Area, 1930-31. Ibid., Vol. XVIII, No. 1.

Russelt, F. S. 1932. On the Biology of Sagitta. II. The Breeding and Growth of Sagitta setosa J. Müller in the Plymouth areas, 1930-31. Ibid., Vol. XVIII, No. 1.

Russeld, F. S. 1933. The Seasonal Distribution of Macroplankton as shown by catches in the 2-metre Stramin Ring-trawl in offshore waters off Plymouth. Journ. Mar. Biol. Assoc., N.S., Vol. XIX, No. 1.

Ruud, J. T. 1929. Biology of Copepods off Möre, 1925-1927. Int. Cons. Explor. Mer. Rapp. et Procès-Verbaux des Réunions, Vol. LVI.

Runström, Sven. 1932. Eine Uebersicht über das Zooplankton des Herdla-und Hjeltefjordes Bergen Museum Arbok, 1931. Bergen.

Rzoska, J. 1927. Einige Beobachtungen bei Copepoden und andere Fragen ihrer Biologie. Inter. Revue der ges. Hydr. und Hydrogr., Bd. XVII, H. 1-2.

Samojloff, J. V. 1926. Die Zusammensetung der Fauna nach ihrem Alter und die Temperatur des umgebenden Mediums. Bull. de la Soc. de la Natural. de Moscow Sec. Geologique.

Steuer, Adolf. 1923. Bausteine zu einer Monographie der Copepodengattung Acartia. Arb. Zool. Inst. Univer., Insbruck I. 
Steuer, Adolf. 1931. Grössen- und Formvariation der Planktoncopepoden. Sitzungsber. der Akad. der Wiss. in Wien. Mathem. natur. Klasse., Abt. I, Bd. 140, Hft. 1 u. 2.

Störmer, L. 1929. Copepods from Michael Sars Expedition, 1924. Int. Cons. Explor. Mer., Rapp. et Proc. Verb., Vol. LXI.

Vinogradov, A. P. 1927. Sur la détermination du poids des animaux marins. Comptes Rend. de l'Académie de Science de l'U.R.S.S.

Wrтн, C. 1915. Copepoda. I. Calanoida amphascandria. The Danish Ingolf-Exped., Vol. III, Part 4.

Zenkevich, L. 1931. Fish-food in the Barents Sea (Introduction). Reports of the first Session of the State Oceanographical Institute (April 14-22, 1931, Moscow). 
TABLE V.

Measurement of Total Length of Female Calanus (Stage VI o) in Millimetres, 1930.

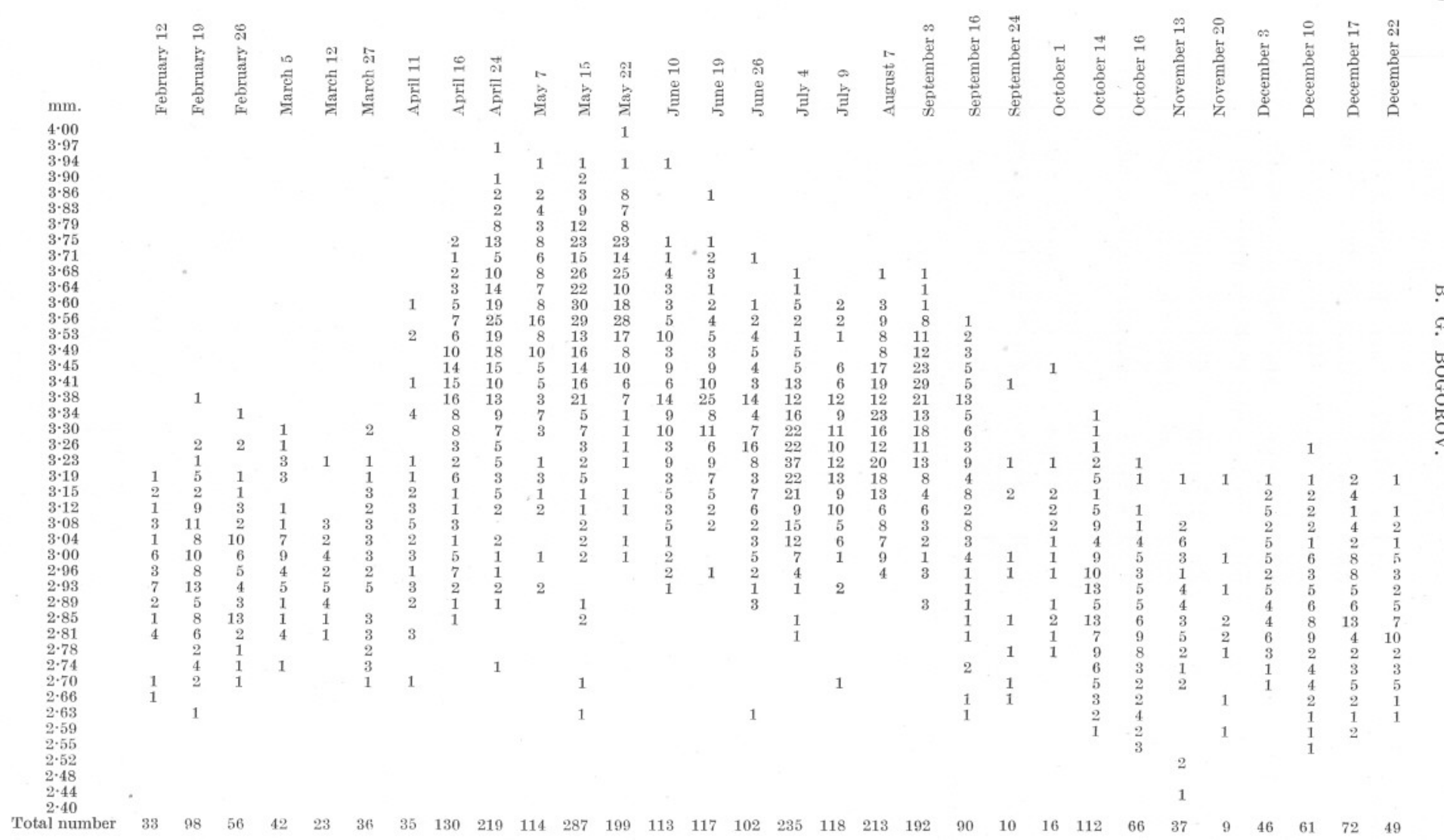

